\title{
Timing major conflict between mitochondrial and nuclear genes in species relationships of Polygonia butterflies (Nymphalidae: Nymphalini)
}

\author{
Niklas Wahlberg*1, Elisabet Weingartner ${ }^{2}$, Andrew D Warren ${ }^{3,4}$ and \\ Sören Nylin²
}

\author{
Address: ${ }^{1}$ Laboratory of Genetics, Department of Biology, University of Turku, 20014 Turku, Finland, ${ }^{2}$ Department of Zoology, Stockholm \\ University, 10691 Stockholm, Sweden, ${ }^{3}$ McGuire Center for Lepidoptera and Biodiversity, Florida Museum of Natural History, University of \\ Florida, SW 34th Street and Hull Road, PO Box 112710, Gainesville, FL 32611-2710, USA and ${ }^{4}$ Museo de Zoología, Departamento de Biología \\ Evolutiva, Facultad de Ciencias, Universidad Nacional Autónoma de México, Apdo. Postal 70-399, México, DF 04510 México \\ Email: Niklas Wahlberg* - niklas.wahlberg@utu.fi; Elisabet Weingartner - elisabet.weingartner@zoologi.su.se; \\ Andrew D Warren - andy@butterfliesofamerica.com; Sören Nylin - soren.nylin@zoologi.su.se \\ * Corresponding author
}

Published: 7 May 2009

BMC Evolutionary Biology 2009, 9:92 doi:10.1/86/147|-2/48-9-92

This article is available from: http://www.biomedcentral.com/I47|-2/48/9/92

(C) 2009 Wahlberg et al; licensee BioMed Central Ltd.

This is an Open Access article distributed under the terms of the Creative Commons Attribution License (http://creativecommons.org/licenses/by/2.0), which permits unrestricted use, distribution, and reproduction in any medium, provided the original work is properly cited.

\begin{abstract}
Background: Major conflict between mitochondrial and nuclear genes in estimating species relationships is an increasingly common finding in animals. Usually this is attributed to incomplete lineage sorting, but recently the possibility has been raised that hybridization is important in generating such phylogenetic patterns. Just how widespread ancient and/or recent hybridization is in animals and how it affects estimates of species relationships is still not well-known.
\end{abstract}

Results: We investigate the species relationships and their evolutionary history over time in the genus Polygonia using DNA sequences from two mitochondrial gene regions (COI and NDI, total $193 \mathrm{I} \mathrm{bP)}$ and four nuclear gene regions (EF-I $\alpha$, wingless, GAPDH and RpS5, total 2948 bP). We found clear, strongly supported conflict between mitochondrial and nuclear DNA sequences in estimating species relationships in the genus Polygonia. Nodes at which there was no conflict tended to have diverged at the same time when analyzed separately, while nodes at which conflict was present diverged at different times. We find that two species create most of the conflict, and attribute the conflict found in Polygonia satyrus to ancient hybridization and conflict found in Polygonia oreas to recent or ongoing hybridization. In both examples, the nuclear gene regions tended to give the phylogenetic relationships of the species supported by morphology and biology.

Conclusion: Studies inferring species-level relationships using molecular data should never be based on a single locus. Here we show that the phylogenetic hypothesis generated using mitochondrial DNA gives a very different interpretation of the evolutionary history of Polygonia species compared to that generated from nuclear DNA. We show that possible cases of hybridization in Polygonia are not limited to sister species, but may be inferred further back in time. Furthermore, we provide more evidence that Haldane's effect might not be as strong a process in preventing hybridization in butterflies as has been previously thought. 


\section{Background}

Phylogenetics at the species-level is becoming increasingly important in the study of processes underlying speciation $[1,2]$. Most species-level phylogenies have until recently been based on only mitochondrial DNA (mtDNA) due to the ease of PCR amplification and its perceived suitability, e.g. due to maternal inheritance (shorter time for coalescence than nuclear DNA (nDNA) because of smaller $\mathrm{N}_{e}$ ), lack of recombination and relatively high mutation rate. However, species phylogenies are not necessarily the same as gene phylogenies $[3,4]$, as different genes might have different histories. Genes involved with speciation, affecting such traits as hybrid incompatibility, as well as sex chromosomes should be more differentiated between species and less likely to introgress than autosomes [5-8]. Different processes such as random sorting of homoplasy, ancient polymorphism and hybridization with gene introgression can obscure patterns of species relationships. Information from different regions of genomes such as mitochondrial DNA, nuclear DNA (from sex chromosomes as well as from autosomes) and microsatellites are thus necessary in investigating the evolutionary history of a group of closely related species.

As species-level molecular phylogenies based on both mitochondrial and nuclear markers have become more common, it has become clear that there is often well-supported conflict between the genomes for certain clades in given phylogenies [9]. Recent work is pointing to major conflict between mtDNA and nuclear DNA in specieslevel phylogenetic analyses [6,9-15]. The conflict is often attributed to ancient or recent hybridization $[9,12-14]$ or incomplete lineage sorting [15]. Hybridization, a wellaccepted process in plants, appears to be more common also among closely related animals than previously thought [16]. Kronforst [17] showed in Heliconius butterflies that gene flow between species can proceed for long periods of time after divergence.

Although phylogenies give us a hypothesis of species relationships, they tell us little about the processes involved in diversification on their own. More information is needed to discover reasons for diversification, such as geographic location of specimens used and times of divergence of lineages. Contemporary sympatric species might have been allopatric when the two lineages diverged and without well-sampled species it is even harder to draw any conclusions about movements of species and populations. Knowledge about when divergences of lineages have happened in a given group of species may give insight to the processes behind the conflicts in phylogenetic signal. However, the temporal framework has rarely been studied for such conflicts.

Here we study the relationships of species in the genus Polygonia (Lepidoptera: Nymphalidae), which have been used as model taxa in numerous studies on the evolution of insect-host plant interactions [18-21], phenotypic plasticity in life-history traits $[22,23]$, effects of environment on distribution [24] and insect physiology $[25,26]$. Polygonia is a genus thought to include five Palaearctic species (P. c-album, P. c-aureum, P. egea, P. gigantea and P. interposita), and nine Nearctic species, seven in the United States and Canada (P. comma, P. faunus, $P$. gracilis, $P$. interrogationis, $P$. oreas, $P$. progne and $P$. satyrus $[27,28])$ and two endemic to Mexico (P. g-argenteum and $P$. haroldii). The taxonomic status of some of these species is disputed. Polygonia interposita has been treated as a subspecies of $P$. c-album [29] but was suggested to be a species-level taxon by Churkin [30]. So far, this taxon has not been included in any earlier molecular studies. We have tentatively treated $P$. zephyrus as a species separate from $P$. gracilis [following [31]] although this status is unclear; P. zephyrus is often considered conspecific with $P$. gracilis [32]. These two taxa (P. zephyrus and P. gracilis) are morphologically distinguishable at the extremes of their ranges but between those "ends of a cline" a broad zone exists where intermediate forms occur (ADW pers. obs.). This may be an example of incipient speciation or secondary contact between two species. Earlier, P. oreas was sometimes considered a subspecies of $P$. progne, but in a recent study [33], P. oreas was found to be closely related to P. gracilis.

According to previous analyses, the ancestor of Polygonia was distributed in the Palaearctic and there have been two colonization events into the Nearctic region [33]. The ancestral host plants were most likely "urticalean rosids" (which includes the closely related plant families Urticaceae, Ulmaceae, Cannabaceae and Celtidaceae) [21,34]. Many Polygonia species are still restricted to plants from this group but some species have included additional or shifted completely to other plant families, such as Betulaceae, Ericaceae, Grossulariaceae and Salicaceae. In previous studies [21,34] phylogenetic trees have been used to infer ancestral host plant ranges used by butterflies in the subfamily Nymphalinae. The results imply that when host plant range has expanded, an increase in the rate of net diversification has followed. In order to understand in more detail the dynamics of host plant use and diversification in the Polygonia butterflies in particular, and insects in general, it is necessary to generate a hypothesis of the evolutionary history of the group.

Species of Polygonia have been included in several earlier phylogenetic studies $[33,35,36]$, but the relationships of some species have not been stable and conflict between datasets has been noted [36]. In this study, we present a hypothesis of the evolution of this genus in which all currently accepted species and most subspecies have been included. We then apply a temporal framework in order to illuminate the causes of major conflicts between genomic datasets. 


\section{Results}

Combined analysis with Partitioned Bremer Support (PBS) of the 25-taxon dataset showed that there was strong conflict between the mitochondrial partition and the nuclear partition at almost all nodes within the genus Polygonia (Figure 1). Analysis of the two genomic datasets separately showed that the topology was different at these conflicting nodes (Figure 2). Despite the conflict, there are several well-supported clades at which there is no conflict between datasets. The genus Polygonia without the species Kaniska canace is strongly supported by all datasets. The position of $K$. canace as sister to the genus Nymphalis is not well-supported in the cladistic analyses, but is supported by all Bayesian analyses of combined and separate data. The sister species relationships of $P$. egea and $P$. undina, as well as $P$. comma and $P$. g-argenteum are well supported. The clade containing P. c-album, P. interposita and P. faunus, as well as the clade containing all the rest of the Nearctic species (except P. faunus), are also well-supported.

The level of conflict between the different genomic datasets is particularly evident when comparing the separate analyses, where species relationships are quite different with relatively good support (Figure 2). These topologies were not dependent on method used for analysis, and thus the phylogenetic signal found within the mitochondrial and nuclear datasets appears to be strong. The exception is $P$. gigantea, which receives strong support as the sister to $P$. undina $P$. egea with the nuclear dataset, but lit-

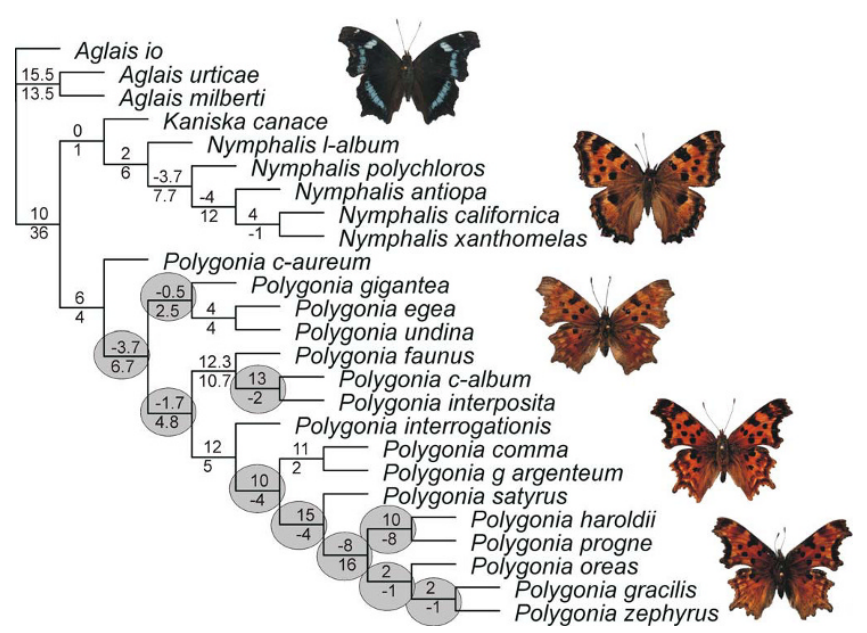

Figure I

Combined analysis of all genes. Values above branches are the Partitioned Bremer Support (PBS) values for the combined mitochondrial gene partition and values below branches are the PBS values for the combined nuclear gene partition. Grey circles highlight nodes with strong conflict within the Polygonia clade. Pictured butterflies are from top to bottom Kaniska canace, Nymphalis polychloros, Polygonia calbum, Polygonia satyrus and Polygonia zephyrus. tle or no support as sister to $P$. c-aureum with the mitochondrial dataset (Figure 2). Interestingly, the estimated times of divergence for clades which are common to the two datasets are similar regardless of which dataset one uses (with the caveat that the confidence intervals are very wide). Thus the Polygonia clade is estimated to have started diverging 18-19 million years ago (mya), the P. c-album to Nearctic Polygonia clade between 13 and 16 mya, the Nearctic Polygonia at 11-12 mya and the P. progne to $P$. gracilis clade between 5 and 6 mya (Figure 2).

Of particular interest in the separate analysis of the mitochondrial and nuclear datasets is the position of $P$. interposita as sister to P. c-album (indeed with almost identical COI haplotypes) based on mtDNA, but as sister to $P . c$ album $+P$. faunus based on nDNA. Also the position of $P$. satyrus as very closely related to $P$. gracilis $+P$. oreas $+P$. zephyrus based on mtDNA, but as sister to $P$. interrogationis $+P . g$-argenteum $+P$. comma based on nDNA. Finally, the position of $P$. oreas as part of the $P$. gracilis $+P$. zephyrus clade based on mtDNA, but as sister to $P$. progne based on nDNA (Figure 2).

Increasing the sample size for each gene region and analyzing them separately brings some light to these patterns. The COI tends to have very little variation within species, but substantial variation between species (Figure 3). The exceptions are $P$. interposita, which is almost identical to $P$. c-album; $P$. g-argenteum, which is very similar to $P$. comma; and $P$. gracilis, $P$. zephyrus and $P$. oreas, which are all very similar to each other even to the point of sharing haplotypes between the three taxa. The position of $P$. satyrus is consistent with the 25-taxon dataset, and shows some variation within the species.

The nuclear gene regions show quite different topologies when analyzed on their own, but several patterns are consistent between them (Figure 4, Figure 5, Figure 6, Figure 7 and Figure 8). First of all, the haplotypes of GAPDH and wgl are very similar in the taxa $P$. gracilis, $P$. zephyrus, $P$. haroldii, $P$. oreas and $P$. progne (Figure 5, Figure 7 and Figure 8). The haplotypes of EF-1 $\alpha, \mathrm{RpS} 5$ and wgl in $P$. satyrus are more related to $P$. comma, $P$. g-argenteum and $P$. interrogationis than to the other Nearctic Polygonia (Figure 4, Figure 6 and Figure 7). The nDNA haplotypes found in $P$. interposita tend to not be especially close to P. c-album (Figure 4, Figure 5, Figure 6 and Figure 7). Interestingly, the haplotypes of RpS5 found in $P$. oreas are very closely related to those found in $P$. progne (Figure 6 and Figure $8 \mathrm{~d})$, while all other nDNA haplotypes are ambiguous about this relationship. Finally, the subspecies P. e. undina is differentiated from $P$. egea for all sequenced genes.

Regarding the haplotype networks, we have focused on the unresolved clade of $\mathrm{P}$. zephyrus, $\mathrm{P}$. gracilis and $\mathrm{P}$. 
a) Mitochondrial genes

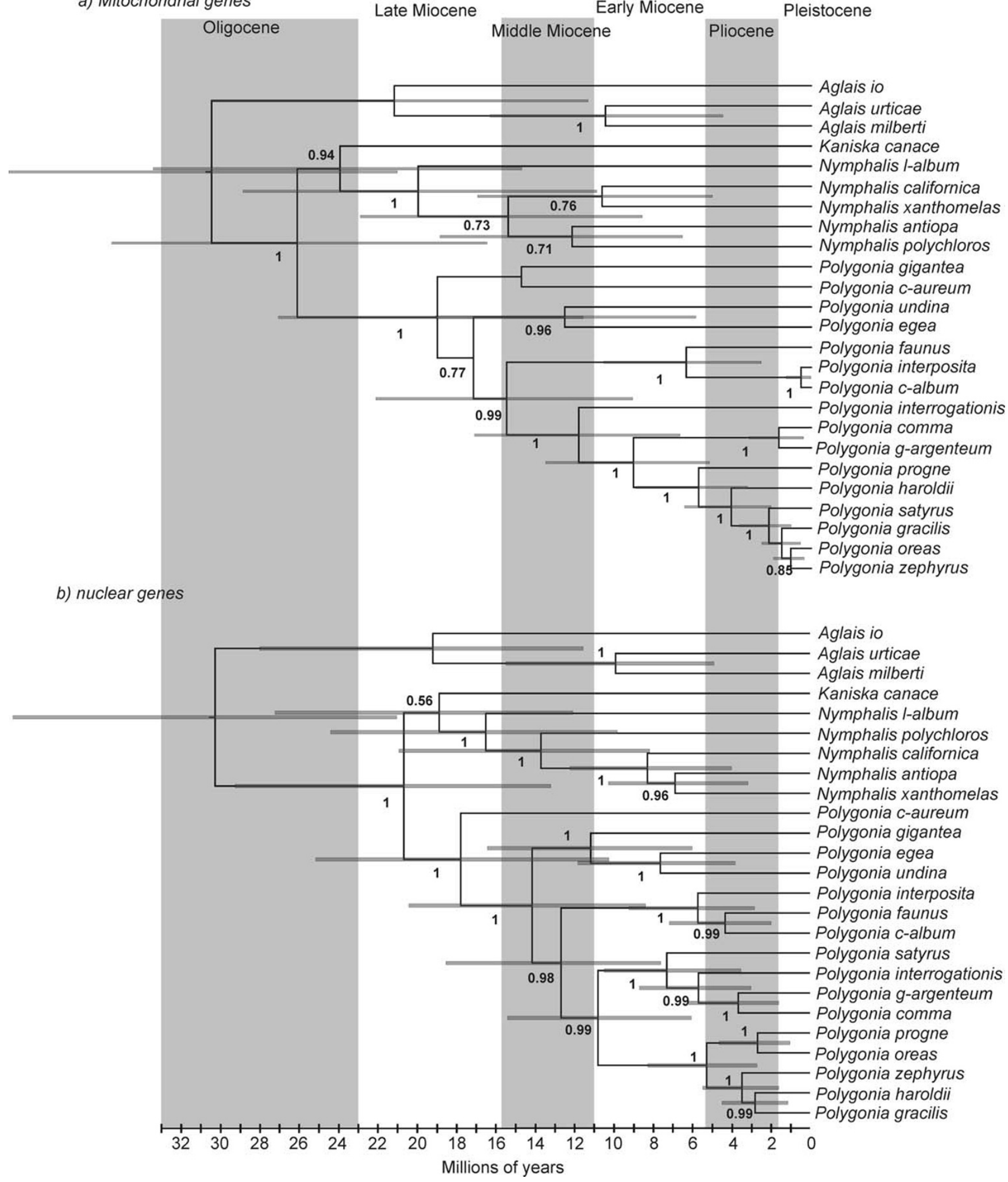

Figure 2

Dated phylogenies of Polygonia. a) based on mtDNA b) based on nDNA. Values below the branches are posterior probabilities for the nodes to the right of the numbers. 
oreas (in COI) as well as the relationships between these species and P. progne and P. haroldii (in RpS5, EF- $1 \alpha$, GAPDH and wgl) (Figure 8). None of the haplotype networks showed a star-like pattern, i.e., a "central" commonly shared haplotype from which other haplotypes deviate by only a few mutational steps, indicative of a rapid and recent diversification [37]. Most haplotypes were only represented by one individual. A few haplotypes were however shared, even between different species. For instance, Polygonia oreas shared the same haplotype with $\mathrm{P}$. gracilis and $\mathrm{P}$. zephyrus in the COI dataset (Figure 8a). In the EF-1 $\alpha$ dataset one P. oreas haplotype is shared with $P$. gracilis (Figure $8 b$ ). Shared haplotypes were found for P. haroldii, P. progne and P. zephyrus in the GAPDH dataset as well as for P. progne, P. zephyrus and P. gracilis (Figure 8c). In the RpS5 dataset P. haroldii, P. zephyrus and P. gracilis shared the same haplotype (Figure 8d). Three haplotypes were shared between $P$. gracilis and P. zephyrus, one haplotype was shared between $\mathrm{P}$. progne and $\mathrm{P}$. gracilis and one haplotype was shared between P. oreas and P. zephyrus in the wgl dataset (Figure 8e). In addition, in the wgl dataset one haplotype is shared between P. comma, P. g-argenteum and all P. satyrus. However, the P. g-argenteum individual had many positions of missing data.

\section{Discussion \\ Major clades in the phylogeny}

Unlinked genes are expected to have independent genealogical histories $[3,38]$, and thus combining data may not always be informative of species relationships [39]. In this study we have found that gene regions from different genomes (mtDNA and nDNA) give rather different estimates of species relationships. The phylogenetic positions of four taxa in particular need explanation: $P$. satyrus, $P$. oreas, $P$. haroldii and $P$. interposita. Each of these is strongly supported in different positions depending on which dataset is analysed. Before we discuss these four anomalous taxa, we will discuss the general findings for the other species, as this is the most complete study of Polygonia phylogeny to date, including several taxa that have never been part of a phylogenetic systematic investigation.

Previous studies have shown conflicting results on the position of the taxon "canace" $[33,35,36]$, often placed in the monotypic genus Kaniska, but suggested to be included in Polygonia by Wahlberg \& Nylin [36]. The present study does not corroborate that finding, but it should be noted that in contrast to the earlier study we did not include morphological data here. However, it is clear that the position of "canace" is not stable and it's sister relationship either to Nymphalis or to Polygonia is weakly supported. In such a case, we feel it is best to retain it in the monotypic genus Kaniska, in order to highlight its "oddity" and long history of independent evolution. This is of course only valid if one accepts the validity of the genera Polygonia and Nymphalis, which some consider to be a single genus Nymphalis, along with our Aglais [e.g., $[40,41]]$. For reasons explained in Wahlberg \& Nylin [36], we feel that the genus Polygonia should be retained, and thus we suggest that the taxon "canace" be retained in the genus Kaniska, as is frequently done in the literature [e.g., [29], e.g., [42,43]].

There are several independent lineages within Polygonia. The type species of the genus, Polygonia c-aureum, is the sister to the rest of Polygonia, as has been found in previous studies $[33,35,36]$. Polygonia gigantea, included here for the first time in a phylogenetic study, is an independent lineage that is most likely sister to the $P$. egea $+P$. undina clade, based on the well-supported result of the nDNA dataset and the ambiguous result of the mtDNA dataset. Polygonia undina has mainly been considered to be a subspecies of $P$. egea, but our results show that it is genetically very distinct and the common ancestor of the two diverged as early as between 8-13 mya (Figure 2). This makes the pair older than several other species pairs in Polygonia, and we found no evidence of interbreeding (all genes were clearly diverged for this pair of species). We thus elevate $P$. undina to the species level (stat. nov.).

The clade containing P. c-album, P. interposita and P. faunus is well-supported and quite clearly the sister to the Nearctic clade. The interrelationships of these three species will be discussed in more detail below. The Nearctic clade including P. satyrus, P. interrogationis, P. comma, P. g-argenteum, $P$. progne, $P$. oreas, $P$. haroldii, $P$. gracilis and $P$. zephyrus, is also well-supported. Within this clade, $P . g$ argenteum (here included for the first time in a phylogenetic analysis) is clearly the sister species to P. comma, and apparently these two have diverged relatively recently (24 mya). The position of $P$. interrogationis with regard to these two species is different with the two genomic datasets. Mitochondrial DNA suggests that it is sister to the rest of the Nearctic species, while nDNA suggests that it is sister to $P$. comma+P. g-argenteum. The latter sister relationship is in fact suggested by morphological data as well [35], giving more weight to this hypothesis of phylogeny.

Our data suggest that $P$. comma and $P$. g-argenteum have diverged in the past 2-3 mya, during which time there has been considerable morphological diversification between them. Adults of $g$-argenteum are among the largest of Polygonia (generally the same size as $P$. interrogationis), and they lack the seasonal polyphenism (expression of dark "summer" forms) seen in P. comma and P. interrogationis. As a result, size excluded, adults of $P$. satyrus and $P . g$ argenteum share a very similar superficial resemblance 


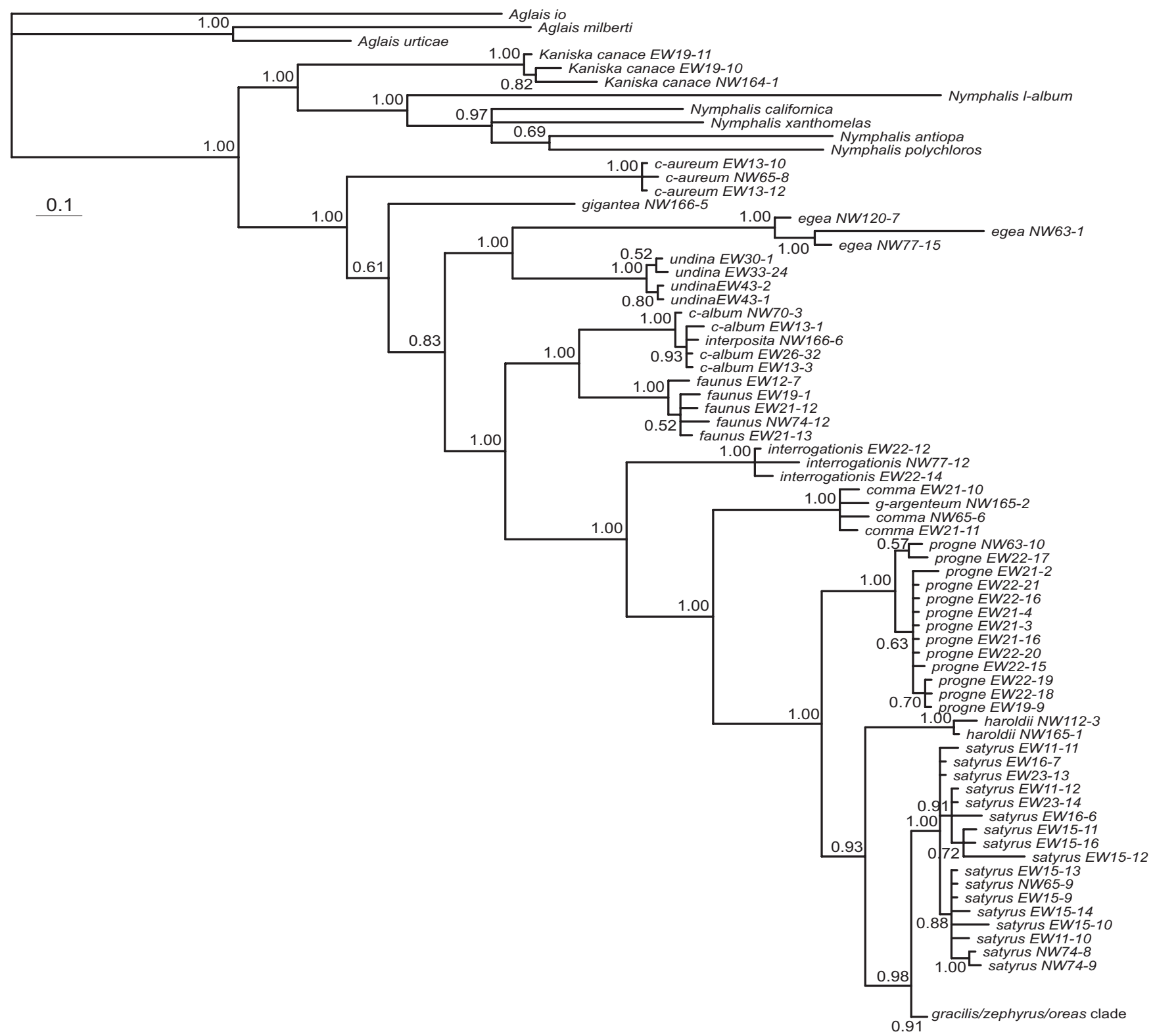

Figure 3

Topology of haplotypes from Bayesian analysis based on the mtDNA COI. Details of gracilis/zephyrus/oreas clade are shown in the haplotype network in Figure 8a. Values below the branches are posterior probabilities for the nodes to the right of the numbers.

(especially in the dorsal view), while adults of $P$. comma (especially dark forms) and $P$. g-argenteum appear quite different at first glance.

As an aside, it is interesting to note that apparently similar patterns of differences between mitochondrial and nuclear DNA are found in the genus Nymphalis (Figure 2). This warrants a separate study to see if similar forces have acted on the sister group of Polygonia.

\section{Ancient mitochondrial introgression in P. satyrus}

Mitochondrial DNA suggests that $P$. satyrus is closely related to $P$. gracilis, $P$. zephyrus and $P$. oreas, whereas nDNA suggests very strongly that $P$. satyrus is sister to $P$. interrogationis, P. comma and P. g-argenteum (Figure 2). Morphological and ecological features, however, suggest that $P$. satyrus is more related to the latter clade. In addition to great overall phenotypic similarity between the adults and immatures of $P$. satyrus and $P$. comma, larvae of 


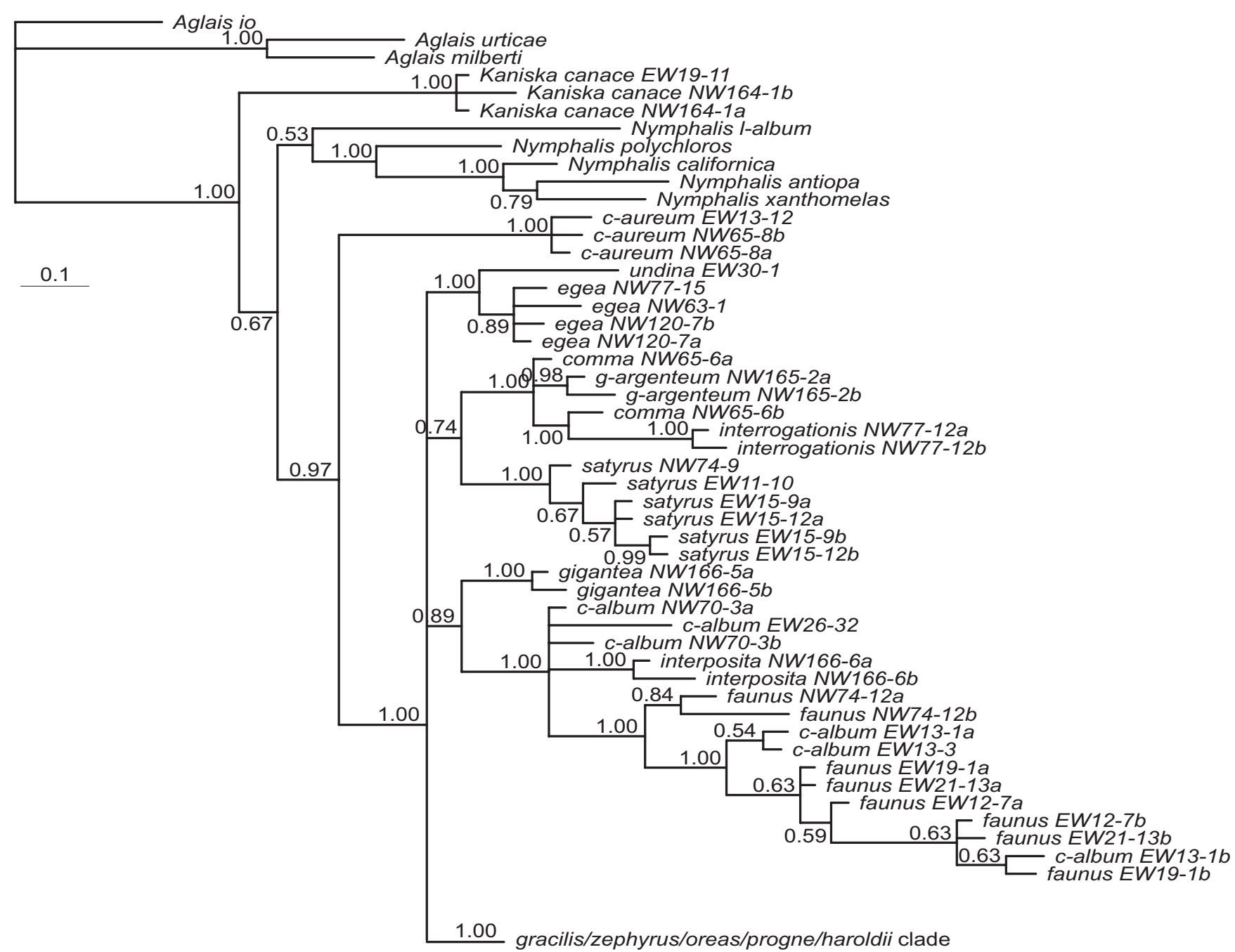

\section{Figure 4}

Topology of haplotypes from Bayesian analysis based on the nDNA EF-I $\alpha$. Details of gracilis/zephyrus/oreas/progne/ haroldii clade are shown in the haplotype network in Figure $8 \mathrm{~b}$. Values below the branches are posterior probabilities for the nodes to the right of the numbers.

those two taxa, as well as those of $P$. interrogationis and $P$. g-argenteum [see [44]], feed on Ulmaceae, Moraceae and Urticaceae as larvae, and late-instar larvae of $P$. satyrus and $P$. comma make very similar larval nests out of altered host plant leaves [45]. Polygonia satyrus is largely parapatric with respect to $P$. comma, as the two fly in sympatry only in a limited portion of northeastern North America, and rarely in eastern Colorado, where $P$. comma is present only as uncommon vagrant individuals from the east [46].

According to our estimates of times of divergence (Figure 2), $P$. satyrus diverged from the ancestral populations between 7-8 mya based on nDNA, whereas the result from mtDNA suggests that the divergence happened much more recently, about 2 mya. Given that the nDNA estimate of divergence time is older than that from
mtDNA, it is possible that the presence of an "alien" mtDNA lineage in $P$. satyrus may be the result of ancient introgression from the ancestor of $P$. gracilis $+P$. zephyrus $+P$. haroldii, which could have happened some 2-3 mya (prior to the onset of the Pleistocene glacial periods). The current sympatric distribution of $P$. satyrus vs. P. gracilis $+P$. zephyrus (the geographic distribution of these taxa is almost identical) highlights the potential for gene exchange in the recent past and present. Given also that all mtDNA haplotypes found to date in P. satyrus are very similar, yet all nDNA haplotypes are more related to the $P$. interrogationis clade, it is possible that repeated population bottlenecks during the glacial cycles have wiped out the original mtDNA lineages from $P$. satyrus, by chance leaving the current introgressed lineage in extant populations. Lack of gene flow during the last 2 million years has 


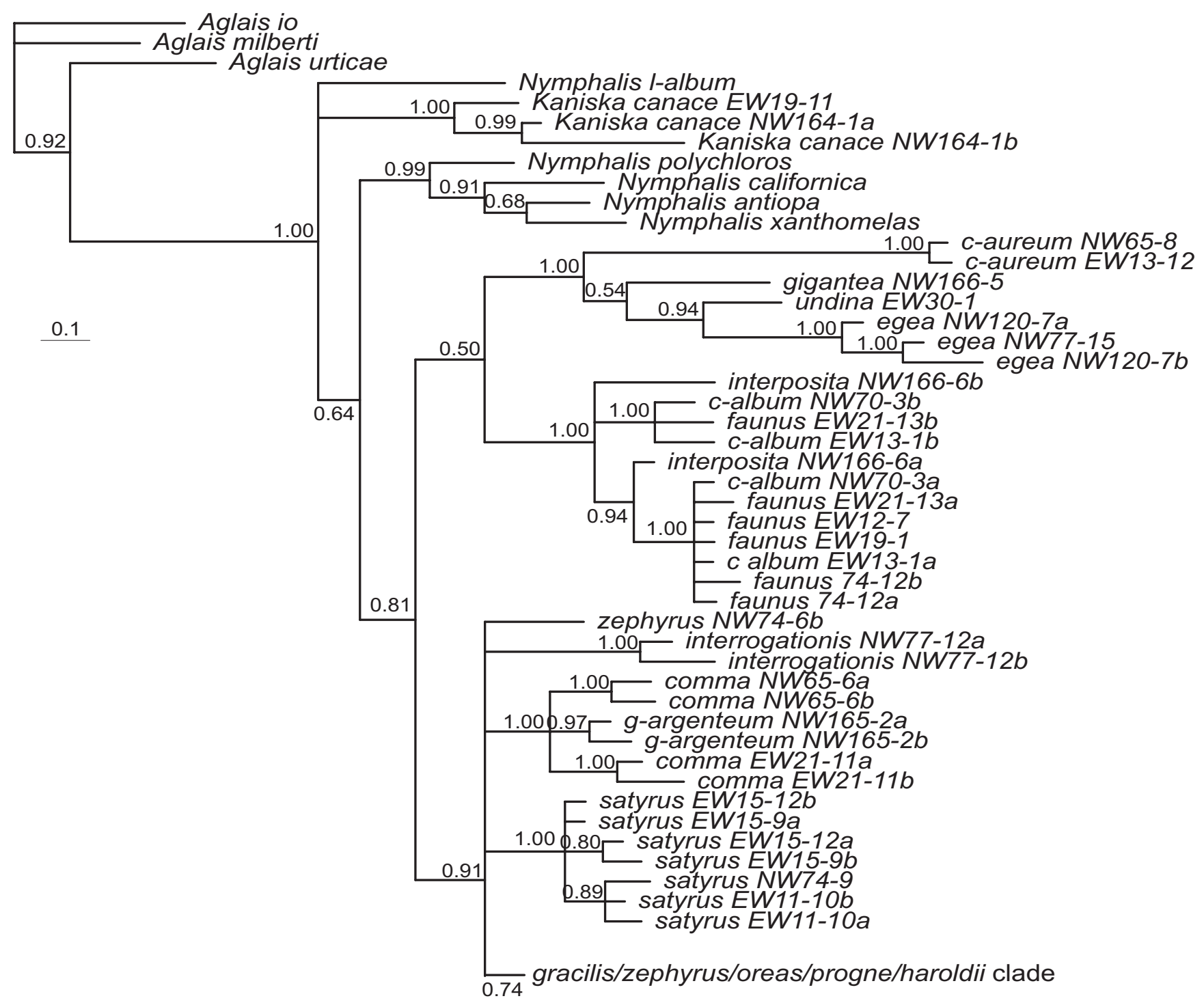

Figure 5

Topology of haplotypes from Bayesian analysis based on the nDNA GAPDH. Details of the gracilis/zephyrus/oreas/ progne/haroldii clade are shown in the haplotype network in Figure 8c. Values below the branches are posterior probabilities for the nodes to the right of the numbers.

now resulted in reciprocal monophyly to evolve in $P$. satyrus and $P$. gracilis $+P$. zephyrus $+P$. haroldii. Such a speculative scenario could be corroborated by more extensive sampling of $P$. satyrus populations across North America, which could make possible coalescense modeling to rule out any possibility that the conflicting results can be explained by ancient polymorphisms $[39,47]$.

In butterflies females are the heterogametic sex and it is accepted that "Haldane's rule" [48] is an important phenomenon, ie. introgression of the maternally inherited mtDNA will not enter the new gene pool due to low viability or sterility of female $\mathrm{F}_{1}$ offspring [see [49]]. Pres- graves [50] showed that hybrid sterility and inviability are common in Lepidoptera and evolve gradually. In those studies of butterflies where both mtDNA and nDNA have been screened, introgression in nDNA but not mtDNA has been found between Papilio machaon and P. hospiton (Papilionidae) [7] as well as between Heliconius cydno and H. melpone (Nymphalidae) $[13,14]$. However, mtDNA introgression has been found between the latter species pair in another study [8], suggesting that the wide acceptance of Haldane's rule needs to be questioned. In the case of Polygonia satyrus we have no knowledge of whether hybrid female offspring are sterile or not, but even if hybrids between contemporary $P$. satyrus and species from 


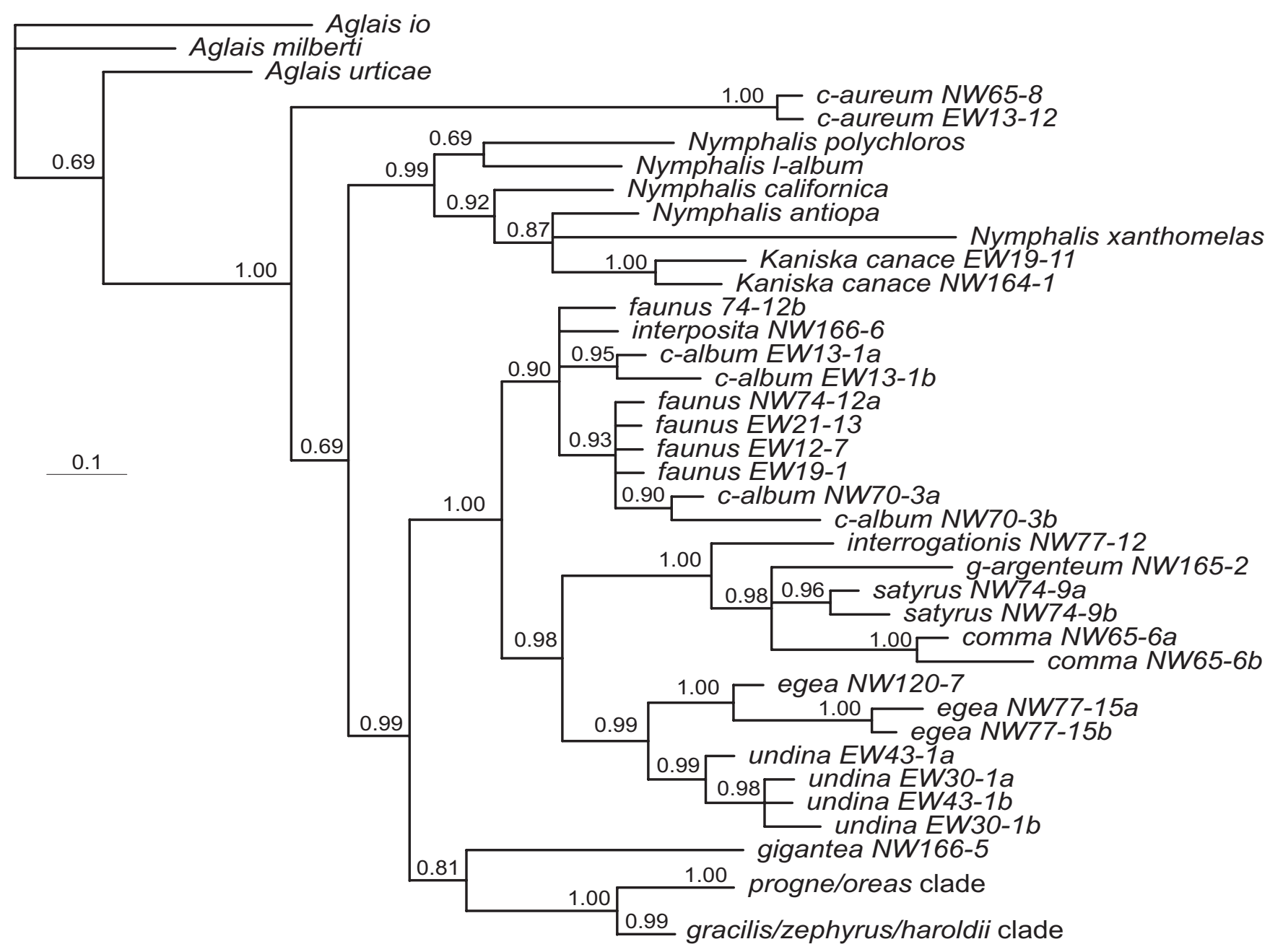

Figure 6

Topology of haplotypes from Bayesian analysis based on the nDNA RpS5. Details of the progne/oreas clade and the gracilis/zephyrus/haroldii clade are shown in the haplotype network Figure 8d. Values below the branches are posterior probabilities for the nodes to the right of the numbers.

the $P$. gracilis clade are inviable this may not have been the case when (if) introgression occured.

\section{Recent mitochondrial introgression in P. oreas}

The mtDNA haplotypes found in $P$. oreas are very similar to those found in P. gracilis and P. zephyrus, and one haplotype is shared between these species. In the nDNA datasets, haplotypes are shared between $P$. oreas, $P$. gracilis and $P$. zephyrus for EF- $1 \alpha$ but not for the other genes, and in the case of RpS5, haplotypes of $P$. oreas are clearly more related to $P$. progne (Figure 4, Figure 5, Figure 6, Figure 7, and Figure 8e). Polygonia oreas has been considered a subspecies of $P$. progne by various authors [e.g., [51]], thus once again, the nDNA dataset corroborates the morphological proposals of previous authors. Interestingly, both the mtDNA and the nDNA datasets suggest that the clade including the five taxa $P$. progne, $P$. oreas, $P$. haroldii, $P$. gra- cilis and $P$. zephyrus began diverging about 5 mya at the end of the Miocene. Based on nDNA, P. oreas and P. progne began diverging about 3 mya, whereas the divergence of $P$. oreas mtDNA is more recent. As with $P$. satyrus, no $P$. oreas COI haplotypes were found to be more related to its probable sister species $P$. progne, and it may be that bottlenecks have wiped out the original mtDNA lineages, while current introgression is introducing new genetic material into $P$. oreas from the $P$. gracilis complex (most likely from western P. zephyrus). On the other hand, we have sampled only 5 individuals of $P$. oreas, and it may be that a denser sampling would reveal mtDNA lineages closer to $P$. progne. Polygonia oreas flies in sympatry and synchrony with $P$. zephyrus throughout the vast majority of its range, the latter usually being much more abundant locally and regionally; thus there are ample opportunities for ongoing introgression between the two taxa. It should be noted 


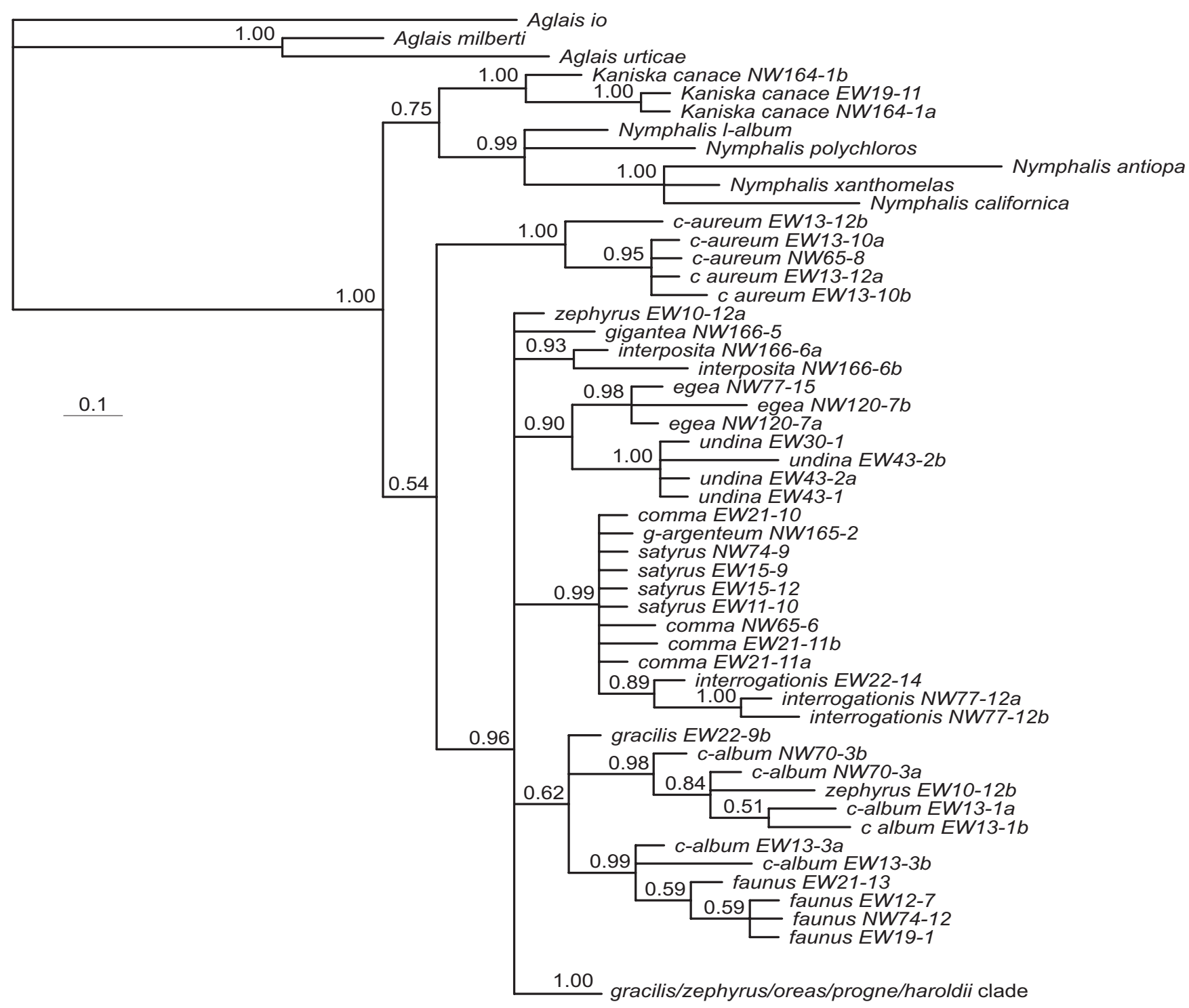

Figure 7

Topology of haplotypes from Bayesian analysis based on the nDNA wgl. Details of the gracilis/zephyrus/oreas/progne/ haroldii clade are shown in the haplotype network Figure 8e. Values below the branches are posterior probabilities for the nodes to the right of the numbers.

that adults of some subspecies of $P$. oreas, especially nigrozephyrus, and some individuals of threatfuli, are so similar to those of sympatric $P$. zephyrus that many experienced lepidopterists cannot distinguish them (without life history information), and these two taxa were not described until 1984 and 2001, respectively (adults of these taxa are still hiding in museum series of $P$. zephyrus all over the world).

\section{Recent speciation of $P$. haroldii and incipient speciation of $\mathbf{P}$. gracilis/zephyrus?}

The taxa $P$. haroldii, $P$. gracilis and $P$. zephyrus appear to be related to one another in a complicated way. Mitochon- drial DNA suggests that $P$. haroldii is a distinct lineage sister to the $P$. gracilis/zephyrus lineage (that includes the "alien" P. satyrus lineage) (Figure 3), yet the nDNA suggests that $P$. haroldii is not distinct from $P$. zephyrus (note that by chance, the $P$. zephyrus chosen for the 25-taxon analyses is rather different from the other P. zephyrus) (Figure 4, Figure 5, Figure 6 and Figure 7). Here the classical explanation for conflicts [52] of recent divergence with not enough time for slowly evolving nuclear genes to have segregated would appear to hold. Interestingly, $P$. haroldii (endemic to mainland Mexico) and some $P$. zephyrus (endemic to western United States and Canada, including northern Baja California, Mexico) nDNA haplotypes 
a)

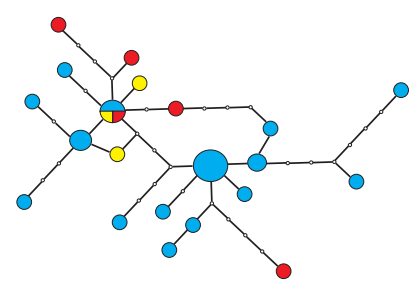

b)

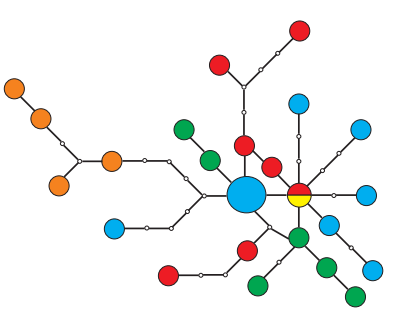

c)

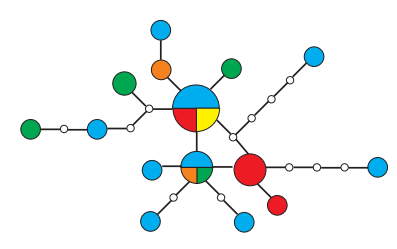

e)

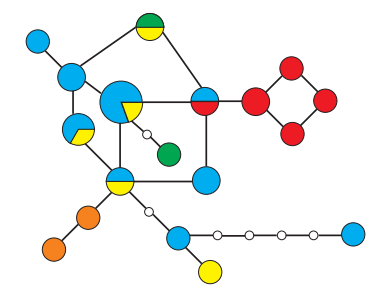

Figure 8

Minimum spanning networks. a) $\mathrm{COI}$ b) EF-I $\alpha$ c) GAPDH d) RpS5 and e) wgl. Size of the circles are directly proportional to the number of individuals with that haplotype. Small white circles indicate a missing haplotype. Each branch is equivalent to one basepair change. Circles with more than one pattern show the proportion of each species. The colour coding are as follows; blue $-P$. zephyrus, red $-P$. oreas, green $-P$. progne, yellow $-P$. gracilis and orange $-P$. haroldii.

appear to be more related to each other, perhaps suggesting recent gene exchange between these western taxa during the Pleistocene glacial periods. Currently, the two taxa appear to be allopatrically distributed. A close relationship between $P$. haroldii and $P$. zephyrus was suggested by Krogen [53], based on morphological similarities. Beutelspacher [54] reported an unidentified species of Urticaceae as a larval foodplant for $P$. haroldii (presumably in the Valley of Mexico), although this record seems unlikely, since $P$. haroldii is usually found in immediate association with Ribes species (Grossulariaceae) (ADW, pers. obs.), the host plant genus utilized by $P$. zephyrus.

Our data suggest that morphological differentiation may occur rapidly in Polygonia, once speciation has occurred. Despite the essentially identical nDNA haplotypes between $P$. zephyrus and $P$. haroldii, the latter has diversified morphologically to the point where it cannot be confused with any other member of the genus. This was perhaps achieved through evolution of a mimetic relationship with the presumably distasteful model Dione moneta (Nymphalidae: Heliconiinae: Heliconiini); in flight, adults of $D$. moneta and $P$. haroldii appear nearly indistinguishable, since the metallic ventral spots of $D$. moneta frequently are not visible (ADW, pers. obs.). Currently, these two species are very often found flying in sympatry and synchrony throughout the Mexican distribution of $P$. haroldii, although the presumed model, $D$. moneta, is usually much more widespread and common than P. haroldii. No obvious geographic variation in morphology has been noted in P. haroldii.

The taxon pair $P$. gracilis and P. zephyrus has been treated as two hypothetically separate species in this study, but the current consensus is that these are subspecies of the same species $[27,28]$. Our results are ambiguous about whether these two taxa are currently diverging or merging. Morphologically, populations of far western P. zephyrus are separable from far eastern populations of $P$. gracilis, but there is a clear cline between the extremes, and populations found in Alberta, Canada, consist mostly of adults that cannot be confidently assigned to one or the other taxon [55]. On the one hand, our data does not distinguish between the two taxa (haplotypes are shared regardless of gene or genome inspected), but on the other hand, haplotypes are also shared with $P$. progne, $P$. haroldii, and $P$. oreas, which are distinct species-level taxa. Thus, detailed elaboration of the taxonomic status of $P$. zephyrus and $P$. gracilis will only be possible once a thorough study can be conducted, considering dozens of populations from throughout the range of the complex. The current distribution of these two taxa, with an apparently broad zone in western Canada where their identities become blurred, suggests ongoing gene flow between them, and a careful study of populations in Alberta seems warranted.

Polygonia interposita, species or subspecies of P. c-album? The rarely collected taxon $P$. interposita is found in central Asian mountains and has often been considered a subspecies of P. c-album [e.g., [43]]. This taxon has frequently been confused with $P$. undina, due to the somewhat similar ventral wing pattern and similar distribution. We were only able to get one specimen of $P$. interposita that gave good quality DNA. The mtDNA of this specimen was almost identical to $P$. c-album (which shows very little variation in COI across its entire range; Weingartner et al. in prep.). The nDNA, however, was quite distinct from $P . c$ album, and indeed in the 25-taxon analysis, $P$. interposita emerged as sister to $P$. $c$-album $+P$. faunus, with a divergence time estimated at about 5 mya. Could this possibly be a similar case to $P$. satyrus in North America? Only 


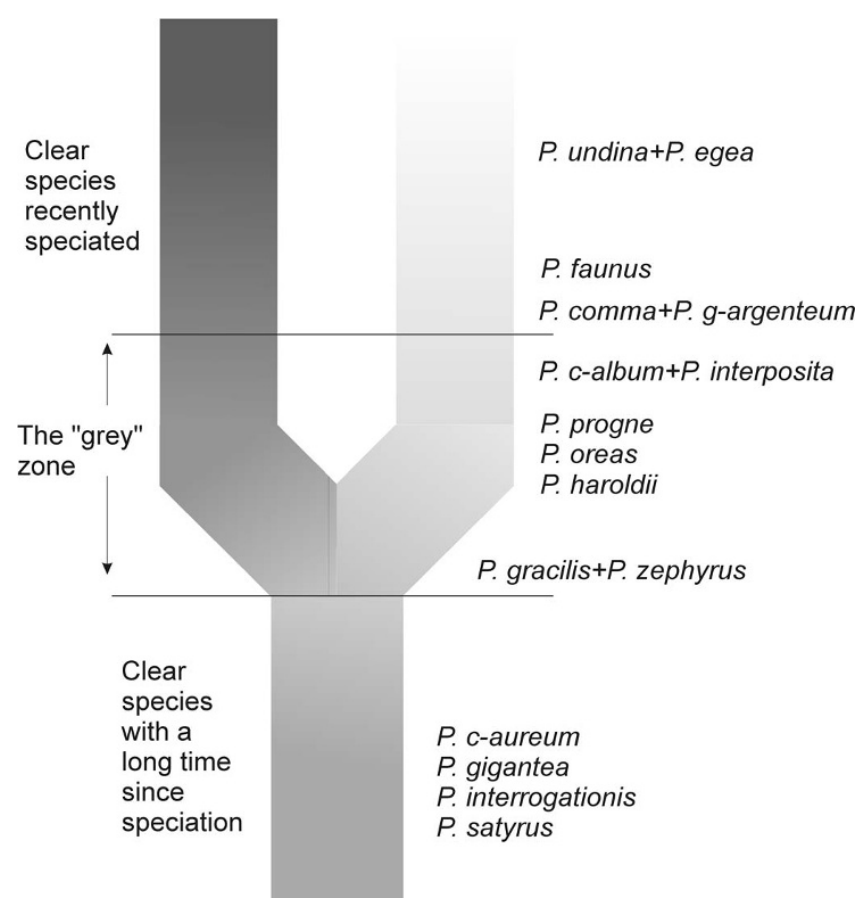

Figure 9

Species through time, a summary of our results. Species below the "grey zone" are clear independent lineages with no known closely related sister species. Species in the "grey zone" are at various stages in the speciation process. Species above the "grey zone" are closely related sister species that are separate genetic entities. They have thus by this time also become clear independent lineages ready for a future new bifurcation, should the right circumstances arise. Figure modified from de Queiroz [58].

more samples of $P$. interposita would shed light on this question, but based on the current specimen, it is possible that the mitochondrial lineage of $P$. c-album has invaded the genome of $P$. interposita in recent times, resulting in a situation where the two genomes give conflicting signals regarding phylogenetic relatedness.

\section{Species as lineages through time}

The concept of species as lineages is fast gaining support from the scientific community [56-59]. The concept takes into account that species are part of an evolutionary continuum from diverging populations to already diverged, well-defined species. Many of the multitude of proposed species concepts lie along this continuum, but are not general enough to explain the diversity we see in nature. Here we present results for a small group of well-known butterflies with a relatively stable taxonomy. Despite molecular data from 6 gene regions for a total of 4879 bp (much more than the standard in species level phylogenetic studies at the moment), we were unable to resolve the relationships of the 16 species unambiguously, mainly due to conflicts between mitochondrial and nuclear gene regions.

Considering the lineage concept, it is clear that $P . c$ aureum, $P$. gigantea, $P$. egea, $P$. undina, $P$. satyrus and $P$. interrogationis have differentiated so long ago that there is no question about their taxonomic status as species (Figure 9). The species-level status of $P$. comma and $P$. g-argenteum, as well as $P$. c-album, $P$. interposita and $P$. faunus also is not really a question based on our results, but they have speciated relatively recently and in the case of $P$. interposita, may still hybridize in nature with P. c-album. In Figure $9, P$. faunus is placed out of the grey zone due to the clear separation of it's populations in North America from those of P. c-album and P. interposita in Eurasia. Further down the continuum closer to the divergence events are $P$. progne, $P$. oreas and $P$. haroldii (Figure 9), which have speciated so recently that occasional gene flow may still occur between $P$. oreas and $P$. progne and/or P. zephyrus, but which remain taxonomic entities separate from their closest relatives. Just above the divergence line, entering into the grey zone of one or two species is the taxon pair P. gracilis and P. zephyrus (Figure 9). To really be able to say whether the two are above or below the line would require population genetic methods to see whether gene flow between the two populations is sufficiently high to consider them conspecific.

\section{Conclusion}

In conclusion, although we now have included considerable amounts of new genetic information in an attempt to interpret the evolutionary history of Polygonia butterflies, we are still not able to fully understand the processes of speciation in this taxon. Especially within the Nearctic clade, more population genetic data is needed. However, our results graphically demonstrate, first, that species in this group evolve over time, sometimes over a very long time, and, second, that evidently even well-differentiated species can hybridize to the extent that different parts of their genome may suggest strongly conflicting patterns of relationships.

The results from the present study do not change the main conclusion from the study of host plant range in Polygonia butterflies [21]. In that paper we introduced the idea that based on the phylogeny it was possible to show that butterfly clades including species that use host plants additional to, or other than, the "urticalean rosids", included more butterfly species than the sister clade (only feeding on "urticalean rosids"). Our present results are still in agreement with the former result and there is no case in which the reverse is valid (that species restricted to "urticalean rosids" constitute more butterfly species than the sister group of species with a broader host plant range). Thus, we believe that being able to expand the host plant 
Table I: Summary of number of individuals per species sequenced for a given gene.

\begin{tabular}{|c|c|c|c|c|c|c|}
\hline \multirow[b]{2}{*}{ Species } & \multicolumn{6}{|c|}{ Number of individuals sequenced } \\
\hline & $\mathrm{COI}$ & NDI & wingless & $\mathrm{EFI}-\alpha$ & GAPDH & RpS5 \\
\hline \multicolumn{7}{|l|}{ Outgroup taxa } \\
\hline Aglais io & I & 1 & 1 & I & I & I \\
\hline Aglais milberti & I & 1 & 1 & 1 & I & I \\
\hline Aglais urticae & I & I & I & I & I & I \\
\hline Nymphalis antiopa & 1 & 1 & 1 & 1 & I & 1 \\
\hline Nymphalis californica & I & I & 1 & I & I & 1 \\
\hline Nymphalis l-album & I & I & 1 & I & I & I \\
\hline Nymphalis polychloros & 1 & 1 & 1 & I & I & I \\
\hline Nymphalis xanthomelas & 1 & 1 & 1 & 1 & I & 1 \\
\hline \multicolumn{7}{|l|}{ Ingroup taxa } \\
\hline Kaniska canace & 3 & 1 & 2 & 2 & 2 & 2 \\
\hline Polygonia c-album & 4 & 1 & 3 & 4 & 2 & 2 \\
\hline Polygonia interposita & I & 0 & 1 & 1 & I & I \\
\hline Polygonia c-aureum & 3 & 1 & 3 & 2 & 2 & 2 \\
\hline Polygonia comma & 3 & 1 & 3 & 1 & 2 & 1 \\
\hline Polygonia egea & 3 & I & 2 & 3 & 2 & 2 \\
\hline Polygonia undina & 4 & 0 & 3 & I & I & 2 \\
\hline Polygonia faunus & 5 & 1 & 4 & 4 & 4 & 4 \\
\hline Polygonia g-argenteum & 1 & 0 & 1 & 1 & 1 & 1 \\
\hline Polygonia gigantea & 1 & 0 & 1 & 1 & I & 1 \\
\hline Polygonia gracilis & 3 & 1 & 2 & I & 2 & 2 \\
\hline Polygonia zephyrus & 24 & 1 & 8 & 6 & 8 & 8 \\
\hline Polygonia haroldii & 2 & I & 2 & 2 & 2 & 2 \\
\hline Polygonia interrogationis & 3 & 1 & 2 & 1 & I & I \\
\hline Polygonia oreas & 5 & i & 4 & 4 & 4 & 4 \\
\hline Polygonia progne & 14 & 1 & 2 & 3 & 2 & 2 \\
\hline Polygonia satyrus & 17 & 1 & 4 & 4 & 4 & 1 \\
\hline
\end{tabular}

See Additional File I for details of individuals, including collection locality and GenBank accession numbers.

range will enhance speciation through colonizations and local adaptations, according to the oscillation hypothesis [60].

We have shown that the species-level relationships inferred from DNA sequence data may be strongly influenced by the markers that have been chosen. This then begs the question of how this phenomenon affects studies aimed at looking at higher levels of phylogenetic relationships, such as genera or families. Fortunately, our previous studies at higher levels have used the same markers as we have in this study [33,61-66], and results show that the COI is generally concordant with the nuclear markers at taxonomic levels above genera. This is probably due to the same stochastic processes that lead to reciprocal monophyly at the species level, i.e. given enough time, lineages (species) will go extinct, leaving sister entities that we call genera (and by default higher taxa) reciprocally monophyletic. This is not to say that all currently described genera are monophyletic entities, simply because the majority of genera have not been rigorously tested for monophyly using phylogenetic analyses.

\section{Methods}

We sampled 96 individuals of all Polygonia species, as well as 8 outgroup species belonging to the genera Nymphalis and Aglais (see Table 1 and Additional File 1). Most individuals were collected by colleagues (see Acknowledgments) and sent dry to Stockholm. Total genomic DNA was extracted from two legs using QIAgen's DNEasy extraction kit, according to the manufacturer's instructions, with the exception that individuals more than 2 years old at extraction were eluted into $50 \mu \mathrm{l}$ of elution buffer, rather than the recommended $200 \mu \mathrm{l}$. Voucher specimens are stored at the Department of Zoology, Stockholm University and Laboratory of Genetics, University of Turku, and can be viewed at http://nymphali dae.utu.fi.

We amplified 6 loci using PCR directly from the genomic extracts. The loci were cytochrome oxidase subunit I (COI) and NADH subunit 1 (ND1) from the mitochondrial genome, and elongation factor-1 $\alpha(\mathrm{EF}-1 \alpha)$, wingless (wgl), glyceraldehyde-3-phosphate dehydrogenase (GAPDH) and ribosomal protein S5 (RpS5) from different nuclear 
genomes. Primers and PCR protocols were taken directly from Wahlberg and Wheat [67], except for ND1, for which we followed the protocol described in Nylin et al. [35]. PCR products were cleaned using exonuclease I and calf intestine alkaline phosphatase (Fementas) and sequenced directly, using either the PCR primers or universal tails attached to the primers [for details, see [67]], on a Beckman-Coulter CEQ8000 capillary sequencer (Stockholm), or an ABI PRISMR 3130xl capillary sequencer (Turku) using dye terminator sequencing kits according to the recommendations of manufacturers.

All six genes were initially amplified for a selection of 25 taxa (8 outgroup species and 17 taxa of Polygonia). In order to verify patterns of strong conflict between the mitochondrial and nuclear genes [33,36], a further 77 individuals of Polygonia and four individuals of Kaniska canace were amplified and sequenced for COI, 27 individuals of Polygonia for EF- $1 \alpha, 30$ individuals of Polygonia for wgl, 23 individuals of Polygonia for GAPDH and 20 individuals of Polygonia for RpS5. Two individuals of Kaniska canace were amplified and sequenced for all nuclear genes.

Resulting chromatograms were examined by eye in BioEdit [68] and any heterozygous positions (two equally sized peaks observed at one position) were coded with IUPAC ambiguity codes. All sequences are from proteincoding genes and thus alignment was trivial. As noted in previous publications $[33,35,36]$, a one-codon deletion was inferred in the wgl sequence of the three species of Aglais. Heterozygous sequences were separated manually into haplotypes. For sequences with only one heterozygous position, this was trivial. For those with two or more heterozygous positions, one haplotype was assumed to be identical to a common haplotype found in other individuals of the same species. This was possible in all cases.

The previously noted strong conflict between two mitochondrial and two nuclear genes $[33,36]$ was investigated with a total evidence approach and Partitioned Bremer Support (PBS) on the 25-taxon dataset. Results suggested that mitochondrial and nuclear partitions continued to conflict with the addition of new nuclear gene regions. We thus analysed the combined mitochondrial genes and the combined nuclear genes to obtain estimates of relationships based on the mitochondrial genome and the nuclear genome, respectively. The two genome sets were analysed separately, but combined within each set (ie. COI+ND1 and EF- $1 \alpha+\mathrm{GAPDH}+\mathrm{RpS} 5+\mathrm{wgl}$ ) and will be referred to as the mitochondrial data and the nuclear data, respectively. Parsimony analyses were conducted using a heuristic search algorithm in the program TNT [69] on the equally weighted data set. The data were subjected to 100 random addition rounds of successive Sectorial, Ratchet, Drift and Tree Fusing searches [70-72]. We evaluated the character support for the clades in the resulting cladograms using Bremer support $[73,74]$ and Partitioned Bremer support $[75,76]$. The scripting feature of TNT was used to calculate these values [see [64]].

Bayesian inference of phylogeny and times of divergence were estimated using the program BEAST v1.4.6 [77]. Both datasets were analysed under the GTR $+\Gamma$ model with a relaxed clock, allowing branch lengths to vary according to an uncorrelated Lognormal distribution [78]. The tree prior was set to the Yule process, and the "treeModel.RootHeight" prior (i.e., the age at the root of the tree) was set to 33 million years (with a standard deviation of 5 million years), in accordance with results from Wahlberg [79]. All other priors were left to the defaults in BEAST. Parameters were estimated using 2 independent runs of 1 million generations each (with a pre-run burnin of 10000 generations), with parameters sampled every 1000 generations. Convergence was checked in the Tracer v1.4.6 program and summary trees were generated using TreeAnnotator v1.4.6, both part of the BEAST package.

To confirm that Bayesian analyses converged on the same topology, the data were also analyzed with MrBayes 3.1 [80]. The Bayesian analysis was performed on the combined data set with parameter values estimated separately for each gene region using the "unlink" command and the rate prior (ratepr) set to "variable". The analysis was run twice simultaneously for 2 million generations, with four chains (one cold and three heated) and every $500^{\text {th }}$ tree sampled. The first 500 sampled generations discarded as burn-in (based on a visual inspection of when log likelihood values reached stationarity), leaving 3501 sampled generations for the estimation of posterior probabilities. Results of the two simultaneous runs were compared for convergence using Tracer v1.4.6 [77].

The expanded single-gene datasets were analysed separately after separating heterozygotes into haplotypes. These datasets were analysed using both parsimony and Bayesian methods in TNT and MrBayes 3.1, respectively. Search parameters were as above, except the single datasets were not partitioned in any way.

In order to further investigate the resulting polytomies, we constructed a haplotype network in TCS [81], which shows how haplotypes are connected to each other. In this program, the gene genealogies from DNA sequences are estimated with statistical parsimony according to Templeton et al. [82]. We focused on the Nearctic Polygonia species (excluding $P$. faunus). Regions of missing basepairs were removed and we performed analyses of all Nearctic taxa as well as subsets of clades. The datasets are com- 
prised of $1430 \mathrm{bp}$ for COI, $1240 \mathrm{bp}$ for EF-1 $1 \alpha, 392 \mathrm{bp}$ for wgl, $691 \mathrm{bp}$ for GAPDH and $617 \mathrm{bp}$ for RpS5.

\section{Authors' contributions}

NW, SN and EW conceived the study, EW did most of the labwork, NW and EW carried out the analyses and wrote the manuscript. ADW helped interpret phylogenetic patterns and wrote part of the discussion. All authors partook in discussions during analysis and writing, read and approved the final manuscript.

\section{Additional material}

\section{Additional file 1}

List of specimens sampled in this study. Voucher codes, locality where the taxa were collected and GenBank accession numbers for genes sequenced. Photos of vouchers can be viewed at http://nymphalidae.utu.fi/ db.php.

Click here for file

[http://www.biomedcentral.com/content/supplementary/14712148-9-92-S1.doc]

\section{Acknowledgements}

Thanks to Jorge Llorente, Armando Luis and Isabel Vargas (Museo de Zoología, UNAM, Mexico City) for access to specimens under their care, literature and for providing permits and assistance to ADW. We are also grateful to Anton Chichvarkin, Norbert Kondla, Zdenek Fric, Michel Tarrier, Vladimir Lukhtanov, Andrew B. Martynenko, David Threatful, Jim Beck, Bob Parsons, Runar Krogen, Katy Prudic and Mike Leski for providing specimens used in this study. We thank Bertil Borg and two anonymous referees for useful comments on a previous version of this ms. This study was funded by grants to $\mathrm{SN}$ and NW from the Swedish Research Council, and from the Academy of Finland to NW (grant number I 18369). Partial funding to ADW was provided by DGAPA-UNAM (Mexico City).

\section{References}

I. Barraclough TG, Vogler AP, Harvey PH: Revealing factors that promote speciation. Philos Trans R Soc Lond B Biol Sci 1998, 353:24I-249.

2. Barraclough TG, Vogler AP: Detecting the geographical pattern of speciation from species-level phylogenies. Am Nat 2000, I 55:419-434.

3. Tajima F: Evolutionary relationship of DNA-sequences in finite populations. Genetics 1983, 105:437-460.

4. Nichols R: Gene trees and species trees are not the same. Trends Ecol Evol 2001, 16:358-364.

5. Ting C-T, Tsaur S-C, Wu C-l: The phylogeny of closely related species as revealed by the genealogy of a speciation gene, Odysseus. Proceedings of the National Academy of Sciences USA 2000, 97:5313-5316.

6. Bachtrog D, Thornton K, Clark A, Andolfatto P: Extensive introgression of mitochondrial DNA relative to nuclear genes in the Drosophila yakuba species group. Evolution 2006, 60:292-302.

7. Cianchi R, Ungaro A, Marini M, Bullini L: Differential patterns of hybridization and introgression between the swallowtails Papilio machaon and P. hospiton from Sardinia and Corsica islands (Lepidopera, Papilionidae). Mol Ecol 2003, | 2:|46|-|47|.

8. Salazar C, Jiggins CD, Taylor JE, Kronforst MR, Linares M: Gene flow and the genealogical history of Heliconius heurippa. BMC Evol Biol 2008, 8: 132 .
9. Chan KMA, Levin SA: Leaky prezygotic isolation and porous genomes: rapid introgression of maternally inherited DNA. Evolution 2005, 59:720-729.

10. Sota T, Vogler AP: Incongruence of mitochondrial and nuclear gene trees in the carabid beetles Ohomopterus. Syst Biol 200I, 50:39-59.

II. Sota T: Radiation and reticulation: extensive introgressive hybridization in the carabid beetles Ohomopterus inferred from mitochondrial gene genealogy. Popul Ecol 2002, 44: $145-156$

12. Linnen CR, Farrel BD: Mitonuclear discordance is caused by rampant mitochondrial introgression in Neodiprion (Hymenoptera: Diprionidae) sawflies. Evolution 2007, 61:1417-I438.

13. Bull V, Beltrán M, Jiggins CD, McMillan WO, Bermingham E, Mallet J: Polyphyly and gene flow between non-sibling Heliconius species. BMC Biology 2006, 4: II.

14. Kronforst MR, Young LG, Blume LM, Gilbert LE: Multilocus analyses of admixture and introgression among hybridizing Heliconius butterflies. Evolution 2006, 60:1254-1268.

15. McCracken KG, Sorensen MD: Is homoplasy or lineage sorting the source of incongruent mtDNA and nuclear gene trees in the Stiff-tailed Ducks (Nomonyx-Oxyura)? Syst Biol 2005, 54:35-55.

16. Mallet J: Hybridization as an invasion of the genome. Trends Ecol Evol 2005, 20:229-237.

17. Kronforst MR: Gene flow persists millions of years after speciation in Heliconius butterflies. BMC Evol Biol 2008, 8:98.

18. Nylin S: Host plant specialization and seasonality in a polyphagous butterfly, Polygonia c-album (Nymphalidae). Oikos 1988, 53:38I-386.

19. Janz N, Nylin S: The role of female search behaviour in determining host plant range in plant feeding insects: a test of the information processing hypothesis. Proceedings of the Royal Society of London Series B Biological Sciences 1997, 264:70I-707.

20. Janz N: Sex-linked inheritance of host-plant specialization in a polyphagous butterfly. Proceedings of the Royal Society of London Series B Biological Sciences 1998, 265: 1675-1678.

21. Weingartner E, Wahlberg N, Nylin S: Dynamics of host plant use and species diversity: a phylogenetic investigation in Polygonia butterflies (Nymphalidae). J Evol Biol 2006, 19:483-49I.

22. Nylin S: Seasonal plasticity in life-history traits - growth and development in Polygonia c-album (Lepidoptera, Nymphalidae). Biol J Linn Soc 1992, 47(3):30I-323.

23. Wiklund C, Wickman PO, Nylin S: A sex difference in the propensity to enter direct/diapause development - a result of selection for protandry. Evolution 1992, 46(2):519-528.

24. Bryant SR, Thomas CD, Bale JS: Thermal ecology of gregarious and solitary nettle-feeding nymphalid butterfly larvae. Oecologia 2000, I 22: I- I0.

25. Hiroyoshi S, Mitsuhashi J: Sperm reflux and its role in multiple mating in males of a butterfly Polygonia c-aureum Linnaeus (Lepidoptera: Nymphalidae). J Insect Physiol 1999, 45(2): $107-1 \mid 2$.

26. Tanaka D, Sakurama T, Mitsumasu K, Yamanaka A, Endo K: Separation of bombyxin from a neuropeptide of Bombyx mori showing summer-morph-producing hormone (SMPH) activity in the Asian comma butterfly, Polygonia c-aureum L. J Insect Physiol 1997, 43(2):|97-20|.

27. Opler PA, Warren AD: Butterflies of North America. 2. Scientific Names List for Butterfly Species of North America, North of Mexico. Fort Collins, Colorado, USA: Gillette Museum Publications; 2002.

28. Pelham JP: A catalogue of the butterflies of the United States and Canada, with a complete bibliography of the descriptive and systematic literature. J Res Lepid 2008, 40:.

29. Gorbunov PY: The Butterflies of Russia. Moscow, Russia: Russian Academy of Sciences; 2001.

30. Churkin SV: Taxonomic notes on Polygonia Hubner, [1818] (Lepidoptera, Nymphalidae) with description of a new subspecies. Helios (Moscow) 2003, 4: 132-147.

31. Guppy CS, Shepard JH: Butterflies of British Columbia. UBC Press in collaboration with the Royal British Columbia Museum; 2001.

32. Layberry RA, Hall PW, Lafontaine JD: The Butterflies of Canada. Toronto: University of Toronto Press; 1998. 
33. Wahlberg N, Brower AVZ, Nylin S: Phylogenetic relationships and historical biogeography of tribes and genera in the subfamily Nymphalinae (Lepidoptera: Nymphalidae). Biol J Linn Soc 2005, 86:227-25I.

34. Nylin S, Janz N: Butterfly host plant range: an example of plasticity as a promoter of speciation? Evol Ecol 2009, 23:|37-|46.

35. Nylin S, Nyblom K, Ronquist F, Janz N, Belicek J, Källersjö M: Phylogeny of Polygonia, Nymphalis and related butterflies (Lepidoptera: Nymphalidae): a total-evidence analysis. Zool J Linn Soc 200I, I 32:44I-468.

36. Wahlberg N, Nylin S: Morphology versus molecules: resolution of the positions of Nymphalis, Polygonia and related genera (Lepidoptera: Nymphalidae). Cladistics 2003, 19:213-223.

37. Slatkin M, Hudson RR: Pairwise comparisons of mitochondrialDNA sequences in stable and exponentially growing populations. Genetics 1991, 129:555-562.

38. Maddison WP: Gene trees in species trees. Syst Biol 1997, 46:523-536.

39. Knowles LL, Carstens BC: Delimiting species without monophyletic gene trees. Syst Biol 2007, 56:887-895.

40. Kullberg J, Albrecht A, Kaila L, Varis V: Checklist of Finnish Lepidoptera - Suomen perhosten luettelo. Sahlbergia 200I, 6:45-190.

41. Aarvik L, Berggren K, Hansen LO: Catalogus Lepidopterorum Norvegiae. As, Oslo: Lepidopterologisk arbeidsgruppe, Zoologisk museum, Universitet i Oslo, Norsk institutt for skogsforskning; 2000.

42. Corbet AS, Pendlebury HM: The Butterflies of the Malay Peninsula. Kuala Lumpur, Malaysia 4th edition. 1992

43. Tuzov VK: Nymphalidae part I. In Guide to the Butterflies of the Palearctic Region Volume 5. Edited by: Bozano GC. Milano: Omnes Artes 2003:1-64

44. Maza RGdl, Maza Jdl: Notas sobre el ciclo de vida de Polygonia gargenteum (Dbl y Hew) (Nymphalidae). Revista de la Sociedad Mexicana de Lepidopterología 1977, 3:35-4l.

45. Scott JA: The Butterflies of North America. Stanford: Stanford University Press; 1986.

46. Ferris CD, Brown F: Butterflies of the Rocky Mountain States. Norman, Oklahoma, USA: University of Oklahoma Press; 198I.

47. Good JM, Hird S, Reid N, Demboski JR, Steppan SJ, Martin-Nims TR, Sullivan J: Ancient hybridization and mitochondrial capture between two species of chipmunks. Mol Ecol 2008, I 7:1313-1327.

48. Haldane JBS: Sex ratio and unisexual sterility in animal hybrids. J Genet 1922, 12:101-109.

49. Sperling FAH: Butterfly species and molecular phylogenies. In Butterflies: Evolution and Ecology Taking Flight Edited by: Boggs CL, Watt WB, Ehrlich PR. Chicago: University of Chicago Press; 2003:431-458.

50. Presgraves DC: Patterns of postzygotic isolation in Lepidoptera. Evolution 2002, 56: I 168-II83.

51. Scott JA: A review of Polygonia progne (oreas) and P. gracilis (zephyrus) (Nymphalidae), including a new subspecies from the southern Rocky Mountains. J Res Lepid 1984, 23:197-210.

52. Avise JC: Phylogeography: The History and Formation of Species. Cambridge, MA: Harvard University Press; 2000.

53. Krogen R: Records of Polygonia haroldi (Dewitz, I877) in Sonora, Mexico. Atalanta 2000, 3 I:67-70.

54. Beutelspacher CR: Mariposas dirunas del Valle de México. México City: Ediciones Científicas La Prensa Médica Mexicana; 1980.

55. Bird CD, Hilchie G], Kondla NG, Pike EM, Sperling FA: Alberta Butterflies. Edmonton: Provincial Museum of Alberta; 1995.

56. O'Hara RJ: Systematic generalization, historical fate, and the species problem. Syst Biol 1993, 42:231-246.

57. O'Hara RJ: Evolutionary history and the species problem. Am Zool 1994, 34:12-22.

58. de Queiroz K: The general lineage concept of species, species criteria, and the process of speciation. In Endless Forms: Species and Speciation Edited by: Howard DJ, Berlocher SH. Oxford: Oxford University Press; 1998:57-75.

59. de Queiroz K: Species concepts and species delimitation. Syst Biol 2007, 56:879-886.

60. Janz N, Nylin S, Wahlberg N: Diversity begets diversity: host expansions and the diversification of plant-feeding insects. BMC Evol Biol 2006, 6:4.

61. Wahlberg N, Weingartner E, Nylin S: Towards a better understanding of the higher systematics of Nymphalidae (Lepidoptera: Papilionoidea). Mol Phylogenet Evol 2003, 28:473-484.
62. Wahlberg N, Braby MF, Brower AVZ, de Jong R, Lee M-M, Nylin S, Pierce N, Sperling FA, Vila R, Warren AD, et al.: Synergistic effects of combining morphological and molecular data in resolving the phylogeny of butterflies and skippers. Proc $R$ Soc Lond B Biol Sci 2005, 272:1577-I586.

63. Wahlberg $\mathrm{N}$, Freitas $\mathrm{AVL}$ : Colonization of and radiation in South America by butterflies in the subtribe Phyciodina (Lepidoptera: Nymphalidae). Mol Phylogenet Evol 2007, 44: $1257-1272$.

64. Peña C, Wahlberg N, Weingartner E, Kodandaramaiah U, Nylin S, Freitas AVL, Brower AVZ: Higher level phylogeny of Satyrinae butterflies (Lepidoptera: Nymphalidae) based on DNA sequence data. Mol Phylogenet Evol 2006, 40:29-49.

65. Peña C, Wahlberg N: Prehistorical climate change increased diversification of a group of butterflies. Biology Letters 2008, 4:274-278.

66. Warren AD, Ogawa JR, Brower AVZ: Phylogenetic relationships of subfamilies and circumscriptions of tribes in the family Hesperiidae (Lepidoptera: Hesperioidea). Cladistics 2008, 24:642-676.

67. Wahlberg N, Wheat CW: Genomic outposts serve the phylogenomic pioneers: designing novel nuclear markers for genomic DNA extractions of Lepidoptera. Syst Biol 2008 57:231-242.

68. Hall TA: BioEdit: a user-friendly biological sequence alignment editor and analysis program for Windows 95/98/NT. Nucl Acids Symp Ser 1999, 41:95-98.

69. Goloboff PA, Farris JS, Nixon KC: T. N. T. (Tree Analysis using New Technology). Published by the authors I.0th edition. 2004 [http://www.cladistics.com]

70. Goloboff PA: Analyzing large data sets in reasonable times: solutions for composite optima. Cladistics 1999, I 5:415-428.

7I. Nixon KC: The parsimony ratchet, a new method for rapid parsimony analysis. Cladistics 1999, I 5:407-4|4.

72. Moilanen A: Searching for most parsimonious trees with simulated evolutionary optimization. Cladistics 1999, I 5:39-50.

73. Bremer $\mathrm{K}$ : The limits of amino acid sequence data in angiosperm phylogenetic reconstruction. Evolution 1988, 42:795-803.

74. Bremer K: Branch support and tree stability. Cladistics 1994 10:295-304

75. Baker RH, DeSalle R: Multiple sources of character information and the phylogeny of Hawaiian drosophilids. Syst Biol 1997, 46:654-673.

76. Gatesy J, O'Grady P, Baker RH: Corroboration among data sets in simultaneous analysis: hidden support for phylogenetic relationships among higher level artiodactyl taxa. Cladistics 1999, 15:27|-3|3.

77. Drummond AJ, Rambaut A: BEAST: Bayesian evolutionary analysis by sampling trees. BMC Evol Biol 2007, 7:2। 4 .

78. Drummond AJ, Ho SYW, Phillips MJ, Rambaut A: Relaxed phylogenetics and dating with confidence. Plos Biology 2006, 4(5):699-7I0.

79. Wahlberg N: That awkward age for butterflies: insights from the age of the butterfly subfamily Nymphalinae. Syst Biol 2006 , 55:703-7|4

80. Ronquist F, Huelsenbeck JP: MrBayes 3: Bayesian phylogenetic inference under mixed models. Bioinformatics 2003 , 19:1572-1574.

8I. Posada D, Crandall KA: TCS: a computer program to estimate gene genealogies. Mol Ecol 2000, 9: |657-|660.

82. Templeton AR, Crandall KA, Sing CF: A cladistic analysis of phenotypic associations with haplotypes inferred from restriction endonuclease mapping and DNA sequence data. III. Cladogram estimation. Genetics 1992, I32:6 I9-633. 